\title{
Designing an I ntelligent Rehabilitation Wheelchair Vehicle System Using Neural Network-based Torque Control Algorithm
}

\author{
Taeyeun $\mathrm{Kim}^{1}$ and Sanghyun Bae ${ }^{1}$ \\ ${ }^{1}$ Department of Computer Science and Statistics, Chosun University, Gwangju, Korea \\ [e-mail: deerzone@nate.com,shbae@chosun.ac.kr] \\ *Corresponding author: Sanghyun Bae
}

Received September 14, 2017; revised October 27, 2017; accepted November 15, 2017; published December 31, 2017

\begin{abstract}
This paper proposes a novel intelligent wheelchair vehicle system that enables upper limb exercises, lower limb standing exercises and rehabilitation training in a daily life. The proposed system, which can be used to prevent at least the degeneration of body movements and further atrophy of musculoskeletal system functions, considers the characteristics and mobility of the old and the disabled. Its main purpose is to help the old and the disabled perform their daily activities as much as they can, minimizing the extent of secondary disabilities. In other words, the system will provide the old and the disabled with regular and quantitative rehabilitation exercises and diagnosis using the wheelchair-based upper/lower limb rehabilitation vehicle system and then verify their effectiveness. The system comprises an electric wheelchair, a biometric module to identify individual characteristics, and an upper/lower limb rehabilitation vehicle. In this paper the design and configuration of the developed vehicle is described, and its operation method is presented. Moreover, to verify the tracking performance of the proposed system, dangerous situations according to biosignal changes occurring during the rehabilitation exercise of a non-disabled examinee are analyzed and the performance of the upper/lower limb rehabilitation exercise function depending on muscle strength is evaluated through a neural network algorithm.
\end{abstract}

Keywords: Rehabilitation Vehicle, Upper and Lower Limb Rehabilitation, Wheelchair Vehicle, Torque Control, Neural Networks 


\section{Introduction}

Along with the advancement in medical technologies in recent years, an increase in the old with difficulty in an independent life and people with acquired disabilities caused by spinal injuries and apoplexy hemiplegia has emerged as a new social problem. Most of them hope to participate in an active social life, wishing to enjoy the same quality of life as normal people do in various aspects of their lives. Therefore, as part of an effort to facilitate their social activities, it is urgent to develop a rehabilitation vehicle to substitute or supplement their incomplete functions of sensory, judgment and motion.

A rehabilitation vehicle plays a leading or supplementing role during rehabilitation treatment; as such, it can assist the old and the disabled in their functions and daily activities and help them return to society. It can also solve the problems of increasing treatment costs, duration of treatment, and intensity of sustained treatment for those needing rehabilitation treatment [1][2]. As maintaining and improving the state of body movement requires sustained rehabilitation therapies, it is desirable that rehabilitation treatment be performed continuously in daily life regardless of time and place. However, rehabilitation services in South Korea are currently provided in limited facilities such as rehabilitation centers, nursing facilities, and general hospitals; not only are most of these rehabilitation facilities concentrated in the cities but they are also significantly lacking in number. In addition, the time for rehabilitation treatment is usually limited to once a day for one to two hours per session, making sustained rehabilitation treatments impossible.

As the number of the old and the disabled increases and the social interest in welfare grows, the necessity for vehicular technology in the field of rehabilitation has expanded as part of an effort to enhance the quality of life and save medical costs through independent daily activities and sustained rehabilitation treatments,

As for rehabilitation vehicle technology, there are ongoing studies on wheelchair-based rehabilitation vehicles, including the researches on the operation of an electric wheelchair [3], the implementation of an obstacle avoidance and navigation function using a sensor in an intelligent electric wheelchair [4] and the wheelchair driving through the recognition of the user's intention using EEG [5][6][7]. Upper limb rehabilitation vehicle research includes the following: (i) KARES I [8][9], a type of wheelchair-mounted manipulator for those unable to use their hands, which can move by detecting pupil movements using the vehicle's camera and shoulder movements using a sensor; (ii) MIT-MANUS [10], with which the user can move to the desired location by looking at the target point on the table and through the monitor; and (iii) a workstation-type vehicle that uses a haptic device [11][12].

The representative research on the lower limb rehabilitation vehicle includes the following: (i) walking support vehicles of an exoskeleton-wearable-type, e.g., SUBAR [13][14], (ii) an exoskeleton vehicle that supports standing and walking for the elderly and the disabled with paralyzed lower limbs [15]; (iii) a rehabilitation vehicle exoskeleton with a weight unloading device; (iv) HAL [16], a wearable vehicle suit; and (v) a treadmill-type walking rehabilitation vehicles, e.g., Lokomat [17][18], which is used by severely disabled people for walking rehabilitation training. Also the researches on cognition-based user intention recognition and expression using brain waves(EEG, fNIRS) as rehabilitation vehicle's cognition/motion rehabilitation technology [19] and motion-based user intention recognition and expression using biosignals(EMG, GSR, etc.) are presently ongoing [20][21][22]. 
However, most of the existing researches on wheelchair-based vehicles are concerned with the intention recognition of the user and autonomous navigation of an electric wheelchair, having more focus on mobility than on rehabilitation. The exoskeleton-wearable type of rehabilitation vehicle has plenty of limitations in use due to the burden of wearing time and weight of the device and the difficulty in calibrating the rotation axis of the human joint to that of the machine, so that it is used to supplement, not to improve muscle strength.

In addition, as the workstation-type upper limb rehabilitation vehicle and the treadmill-type lower limb rehabilitation vehicle occupy much space, they are usually used in limited places like rehabilitation centers, causing plenty of difficulty in sustained rehabilitation in daily life. Therefore, it is of great necessity to research and develop a wheelchair-based rehabilitation vehicle system to help the old and the disabled perform the rehabilitation training in daily life with ease and assure their mobility as their most basic requirement. The wheelchair-based rehabilitation vehicle system is of great advantage to the user's repetitive work without feeling fatigue, securing effective and sustained rehabilitation treatment and mobility in daily life. In addition, the system enables the quantitative measurement of the effect on the patient's recovery after rehabilitation treatments, whose effectiveness can be objectively judged, and it is also expected that constraints in space, time, and cost can be considerably resolved.

This paper proposes a novel intelligent wheelchair vehicle system that enables upper limb exercises, lower limb exercises, standing exercises and rehabilitation training in a daily life. The proposed system, which can be used to prevent at least the degeneration of body movements and further atrophy of musculoskeletal system functions, considers the characteristics and mobility of the old and the disabled. Its main purpose is to help the old and the disabled perform their daily activities as much as they can, minimizing the extent of secondary disabilities. In other words, the system will provide the old and the disabled with regular and quantitative rehabilitation exercises and diagnosis using the wheelchair-based upper/lower limb rehabilitation vehicle system and then verify their effectiveness. The paper is organized as follows. Section 2 describes the configuration and design of the proposed system. Section 3 describes the results of the system implementation. Section 4 describes the performance evaluation of the implemented system. Finally, Section 5 concludes the study and discusses the future directions of the study.

\section{System Configuration and Design}

\subsection{System Configuration Diagram}

The entire system proposed in this paper is designed for the purpose of developing a rehabilitation vehicle of a novel concept that supports functions such as mobility, upper/lower limb rehabilitation and standing exercises in daily life for the old with physical disabilities and the disabled. The basic structure of the proposed system includes an electric wheelchair for the mobility function, an upper/lower limb rehabilitation vehicle system, and a neural network vehicle control system for user-tailored rehabilitation exercise that is performed based on a standing system according to the user's electromyogram (EMG) and biometric information (pulse and respiration). The overall system configuration of this paper is shown in Fig. 1. 


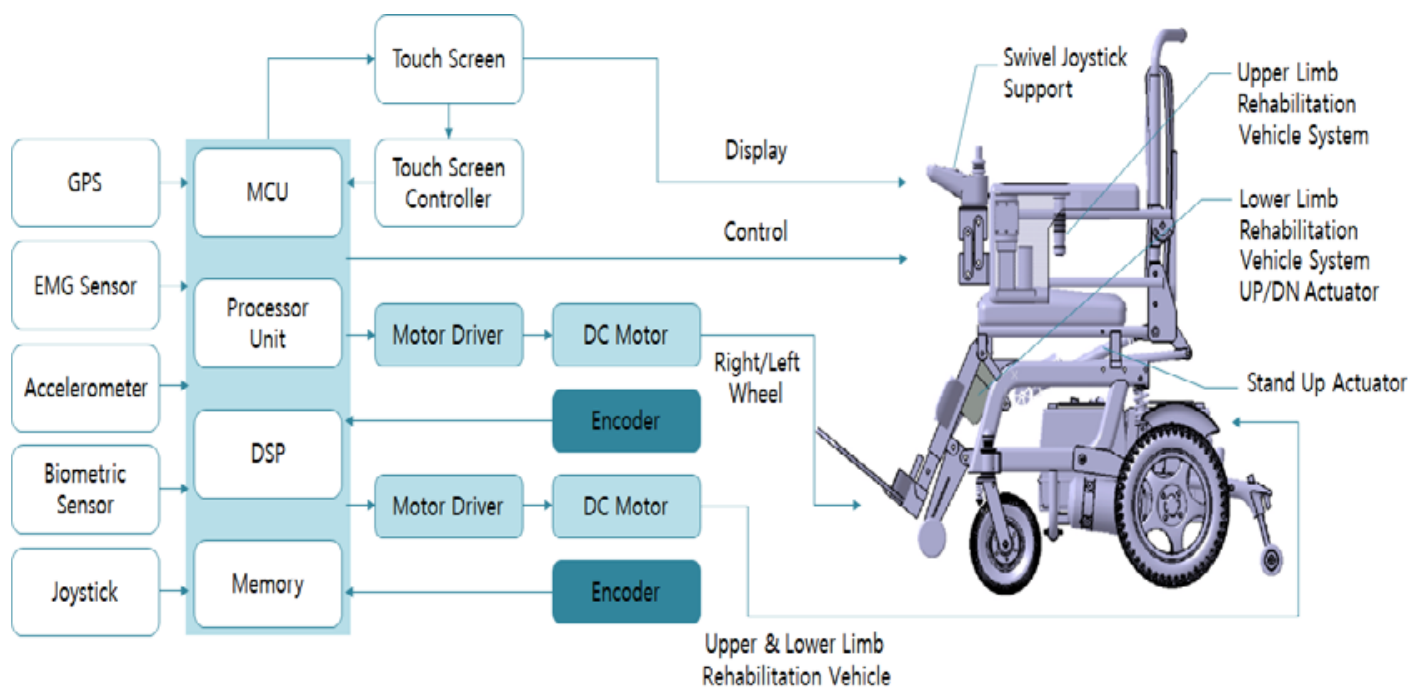

Fig. 1. The system configuration diagram

\subsubsection{Wheelchair Vehicle System}

The wheelchair vehicle system in this paper is designed in two modes: (i) the movement mode that enables the wheelchair to move as a means of movement when sitting and (ii) the standing mode that supports the user's standing exercise. A long ride on a wheelchair can cause secondary health problems like muscle contractures, arthrogryposis, and pressure sores. In addition, when the upper and lower limb rehabilitation exercises are performed while sitting, only the limb muscles are strengthened with low efficiency of the rehabilitation exercise. Therefore, the system proposed in this paper is designed to allow standing exercises to improve the accessibility to the rehabilitation exercise.

The standing exercise allows pelvic movements such as natural pelvic rotation, pelvic inclination, and horizontal pelvic movement as well as vertebral and back muscle exercises, resulting in significantly increased effectiveness of the rehabilitation exercise.

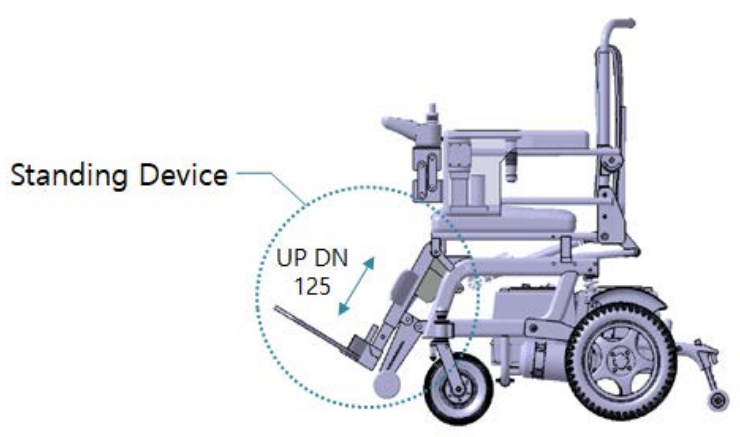

Fig. 2. The integrated standing exercise system

As shown in Fig. 2, the wheelchair rehabilitation vehicle system that enables the standing exercise is designed to be integrated with the upper/lower limb rehabilitation vehicle system 
and can interlock with the standing posture. In particular, by providing a number of steps to the standing angle of the wheelchair vehicle, it is designed to avoid overload on patient's legs.

In addition, a risk detection algorithm is implemented, as shown in Fig. 3, so that the rehabilitation mode operation can be performed only when the tilt angle of the wheelchair, which is measured before the user begins the standing exercise, is less than $5^{\circ}$.

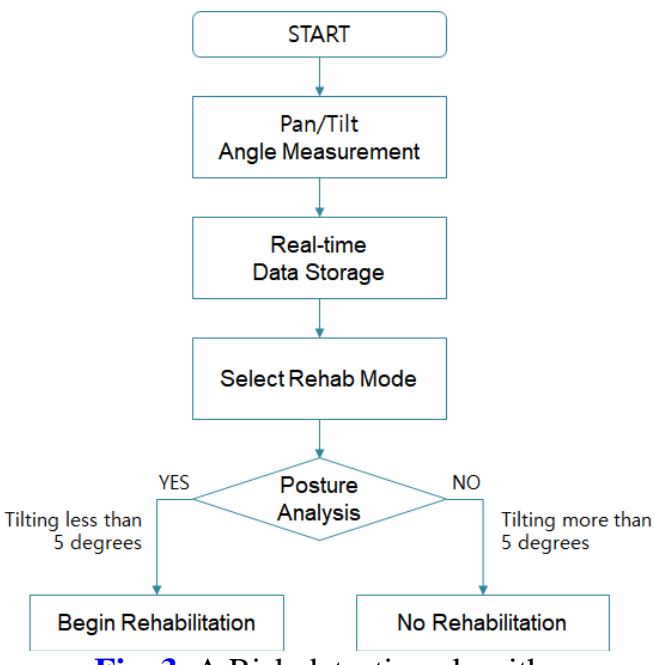

Fig. 3. A Risk detection algorithm

As shown in Fig. 4, the driving control algorithm of the wheelchair is composed of the navigation control and the posture control (standing, backrest, footrest, and seat elevation). The navigation control is achieved by a joystick, and the posture control is designed such that the standing, backrest, footrest, and seat elevation postures can be adjusted by a separate posture controller.

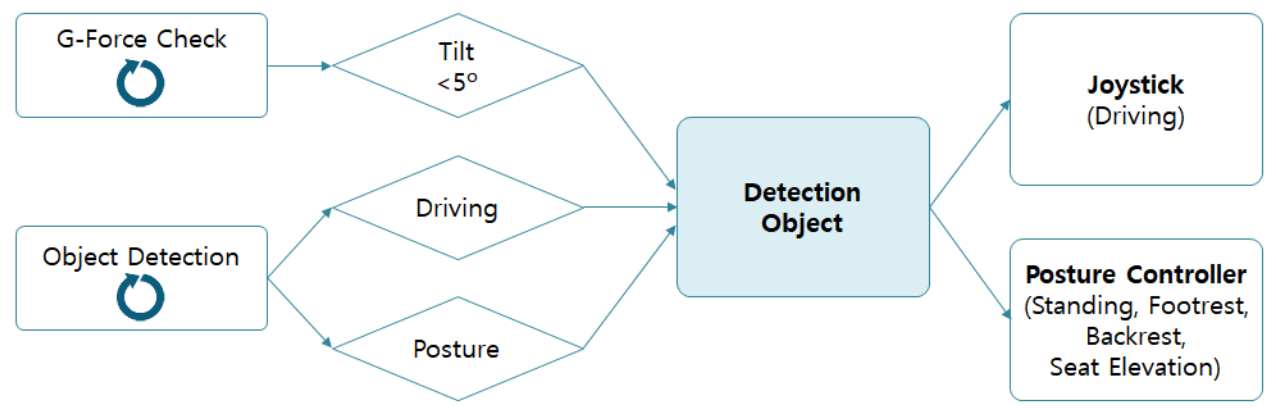

Fig. 4. The driving control algorithm of the wheelchair

\subsubsection{Upper/Lower Limb Rehabilitation Vehicle System}

The upper/lower limb rehabilitation vehicle system, integrated with the wheelchair, is a vehicle capable of rehabilitating the upper and lower limbs, actively supporting the rehabilitation training of the upper and lower limbs using a motor. The upper limb rehabilitation vehicle system has two degree-of-freedom per arm to allow the shoulder and the elbow movements. The lower limb rehabilitation vehicle system is configured to have one 
degree-of-freedom to allow for hip and the knee joint movements, thus having a total of two degree-of-freedom on both legs and two axes are driven by a motor. Fig. 5 shows the configuration of the upper/lower limb rehabilitation vehicle system.
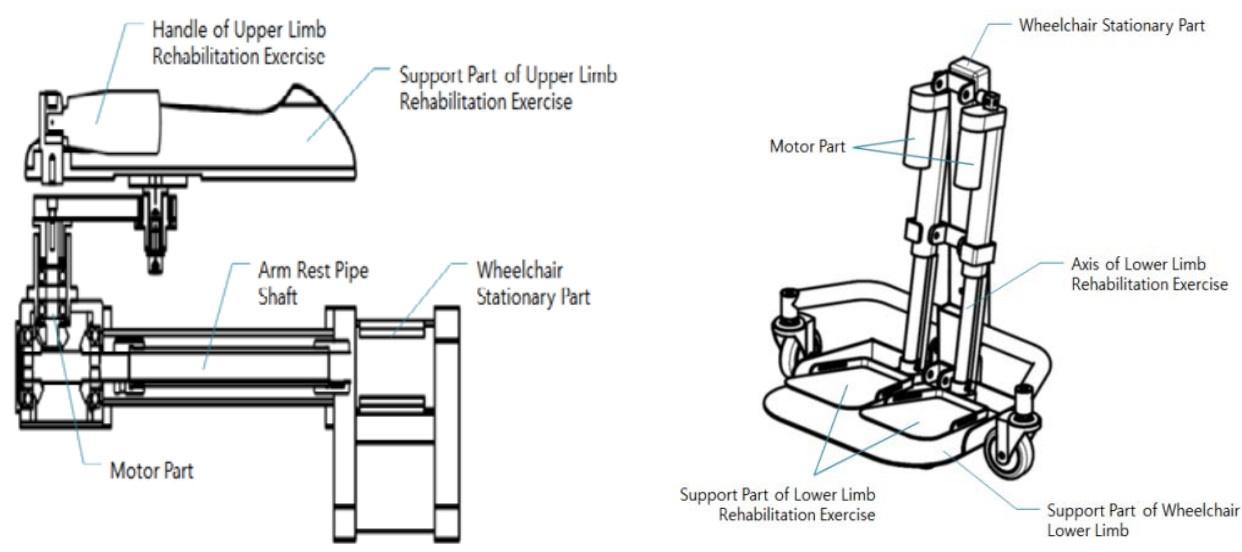

(a) Upper limb rehabilitation system configuration (b) Lower limb rehabilitation system configuration

Fig. 5. The Upper/Lower limb rehabilitation system configuration

The control method of the rehabilitation exercise of the upper/lower limb rehabilitation vehicle is configured in the passive movement mode. The passive movement mode forces the movement of the upper limb vehicle and the lower limb vehicle using a motor power source. The user interface implemented in the system enables the parameters on the exercise intensity, direction, and time for rehabilitation exercises according to the user's choice. In addition, the user's EMG and biosignals (pulse and respiration) are measured to categorize the torque outputs through the data learned by a neural network so that the rehabilitation exercises suitable for the user's characteristic may be possible.

\subsubsection{Intelligent Torque Control System Configuration}

Owing to the powerful function approximation ability of the multi-layer perceptron, a neural network is extremely useful for controlling or identifying nonlinear and complex systems. In this paper, we control the upper/lower limb rehabilitation exercise using a neural network algorithm to intelligently control the torque output based on the user's EMG and biosignals.

As shown in Fig. 6, the total input to the controlled system (plant) is the sum of the feedback control signal and the feedforward control signal calculated from the inverse dynamics model (neural network). Planned trajectory information is used as the input to the neural network, and the feedback control signal is used as the error signal. The advantage of this control structure lies in that it can be stably controlled by the feedback control system even in the initial state where the learning by the neural network has not been completed [23]. 


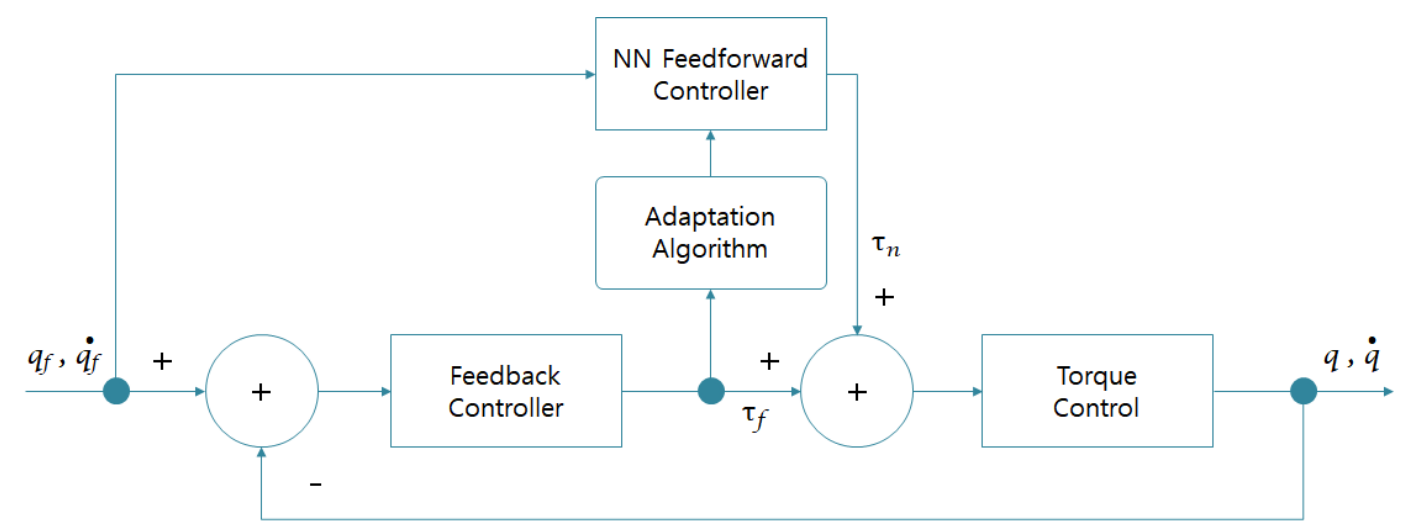

Fig. 6. The intelligent torque control system configuration

Most conventional control schemes produce appropriate control signals only in the vicinity of the operating point. That is, it is possible to perform accurate control only when the controlled system is in a clearly known region. Such a controller will have a poor control performance if uncertainty exists in the system or if unexpected disturbances are added. The neural network controller compensates for this uncertainty, whereby it prevents control performance deterioration.

\subsubsection{User Interface}

To implement the user interface of the intelligent upper/lower limb rehabilitation wheelchair vehicle system proposed in this paper, a tablet PC was attached to the front of the wheelchair as a touchscreen interface. The processing of the signals from the sensor that acquires the information regarding the surrounding environment and the motor control are performed in real time, and the tablet PC is interlinked to the wheelchair vehicle system and used as an auxiliary control board as well as the user interface.

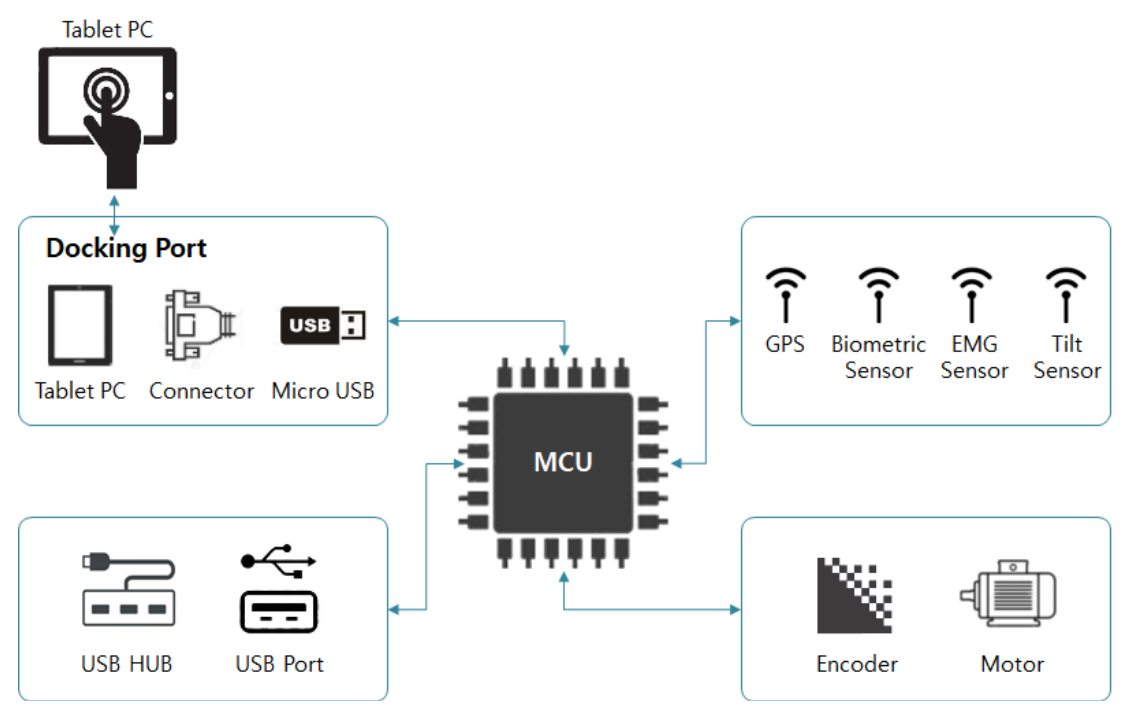

Fig. 7. The tablet PC docking system 
Through the tilt angles displayed on the user interface, the user can ascertain the possibility of standing and monitor the remaining battery capacity, travel range, and rehabilitation exercise functionality of the wheelchair vehicle system. In addition, a GPS program using Google Maps is installed to allow the user to check his or her current location. Fig. 7 shows the configuration of the tablet PC docking system.

Moreover, for efficient rehabilitation exercises, a biosignal analysis system was constructed to measure the user's biometric information (pulse, respiration, and EMG) during the rehabilitation exercise and to feed back the result of the biosignal changes according to rehabilitation through acquired data. Fig. 8 shows the structure of the biosignal analysis system according to the rehabilitation exercise.

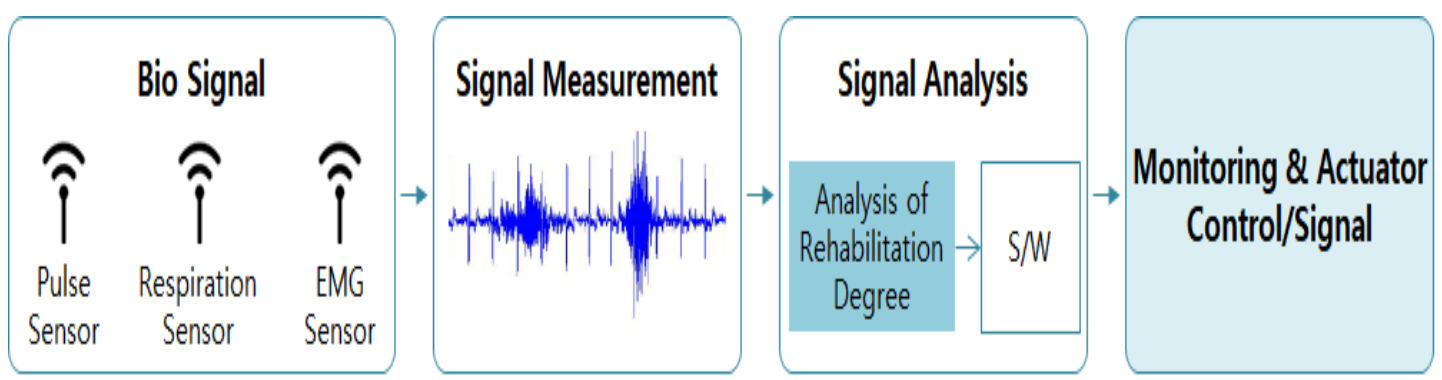

Fig. 8. The biosignal analysis system configuration

The control of the intelligent upper/lower limb rehabilitation wheelchair vehicle system is accomplished by the tablet PC (touchscreen), a joystick, and a posture controller. The navigation control is accomplished by the joystick, the standing control is accomplished by the posture controller, and the control of the upper/ lower limb rehabilitation vehicle can be accomplished on the touchscreen. As the proposed intelligent upper/lower limb rehabilitation wheelchair vehicle system may cause serious risks during the rehabilitation exercises and standing exercises if the sensor information is delayed while the vehicle is in operation, the sensor information and the motor control are designed to proceed in real time.

\subsection{The Proposed Algorithm}

To perform intelligent rehabilitation exercises using the proposed system, formerly measured EMG and biosignals (pulse and respiration) of each user is learned by the neural network, and then the torque output is controlled according to the user's EMG and biosignals to perform user-tailored rehabilitation exercise.

To control the torque value according to the user's muscle strength, the neural network algorithm, which is the most popular among machine learning algorithms, is used in this paper. While there are many ways to adjust the connection strength in a neural network algorithm, it is generally adjusted based on the error between the target coordinate value and the actual output value. Such a process is called the learning rule; in this paper, we used the backpropagation algorithm, which is the most commonly used learning algorithm.

In general, the backpropagation perception algorithm is widely used to provide multi-layer perception in artificial neural network. Multi-layer perception, which retains a similar structure with mono-layer perception, may improve the capability of network by retaining the hidden layer and the in/output characteristic of each Input Nodes non-linear. 
After measuring the user's EMG and general biosignals (pulse and respiration), the measured data are applied to the backpropagation algorithm for learning, and the torque output is controlled according to the classified rating. For the learning through the neural network algorithm, the user's EMG and biometric data (pulse and respiration) are used as the input values. The torque output value classified after the learning of the neural network algorithm is used to categorize the torque output according to the user's muscle strength level based on the muscle spasticity scale (MAS) index [24], which assesses the condition of patients with chronic hemiplegia. Table 1 shows the assessment of the patient's condition using the MAS index. Table 2 shows the classification of torque output levels according to the user's muscle strength, which was applied in this paper.

Table 1. The extent of the assessment in the MAS index that assessed the patient's condition

\begin{tabular}{|c|c|}
\hline Grade & Condition \\
\hline 0 & No increase in muscle tone when the affected limb is moved \\
\hline 1 & $\begin{array}{l}\text { Slight resistance at the end of the range of motion when the affected limb is moved in } \\
\text { flexion or extension, slight increase in muscle tone }\end{array}$ \\
\hline $1+$ & $\begin{array}{l}\text { Slight resistance from below } 1 / 2 \text { of the range of motion when the affected limb is } \\
\text { moved, slight increase in muscle tone }\end{array}$ \\
\hline 2 & $\begin{array}{l}\text { More marked increase in muscle tone through most of the range of motion, but affected } \\
\text { limbs easily moved in flexion }\end{array}$ \\
\hline 3 & $\begin{array}{l}\text { Considerable increase in muscle tone through most of the range of motion, passive } \\
\text { movement difficult. }\end{array}$ \\
\hline 4 & Passive movement impossible in the affected limbs \\
\hline
\end{tabular}

Table 2. The classification of torque output levels according to the user's muscle strength

\begin{tabular}{|c|c|c|c|c|}
\hline $\begin{array}{c}\text { Classified } \\
\text { Level }\end{array}$ & \multicolumn{2}{|c|}{$\begin{array}{c}\text { Muscle Strength } \\
\text { Rating }\end{array}$} & Condition \\
\hline \hline 1 & 0 & Zero & Z & No observable muscle contraction \\
\hline 2 & 1 & Trace & T & $\begin{array}{c}\text { No movement, but perceivable muscle contraction observed } \\
\text { or perceived. }\end{array}$ \\
\hline 3 & $2-$ & Poor- & P- & Partial ROM available without gravity \\
\hline 4 & 2 & Poor & P & Full ROM available without gravity \\
\hline 5 & $2+$ & Poor+ & P+ & Gravity overcome and less than 50\% ROM available \\
\hline 6 & $3-$ & Fair- & F- & Gravity overcome and greater than 50\% ROM available \\
\hline 7 & 3 & Fair & F & Gravity overcome and full ROM available \\
\hline 8 & $3+$ & Fair+ & F+ & Gravity overcome and some resistance overcome and full \\
ROM available
\end{tabular}


The proposed backprpagation algorithm as a supervised learning algorithm, with which the input value and target value are provided is constituted when each neuron controls its connection strength and learned by minimizing the errors after the comparison between output value and target value.

Backpropagation algorithm is divided into two stages. In the first stage the errors between input value and output value is calculated. In the second stage, a mapping relation is formed between input value and output value by adjusting the connection strength between each neuron using delta rule in order to decrease errors. Such error adjustment is transferred from lower layer to higher layer to sense errors and control the connection strength by backpropagating from higher layer(target value) to lower layer(input value) [25].

The practice stages of the proposed algorithm are as follows. Several times of multiplication and addition process between the weight of neural network produces the output(y) as a result of input. The output(y) here is different from the desired output(o)(y-o), generating an equivalent error. ( $\mathrm{e}=\mathrm{y}-\mathrm{o})$ The weight of output layer is renewed in proportion to the error, and then that of hidden layer is renewed, whose direction is opposite to that of neural network process. That is to say the neural network process is proceeded to such directions as Input Layer $\rightarrow$ Hidden Layer $\rightarrow$ Output Layer, the learning process of weight renewal to such directions as Output Layer $\rightarrow$ Hidden Layer [26].

The execution steps of the backpropagation algorithm are performed as shown in Fig. 9.

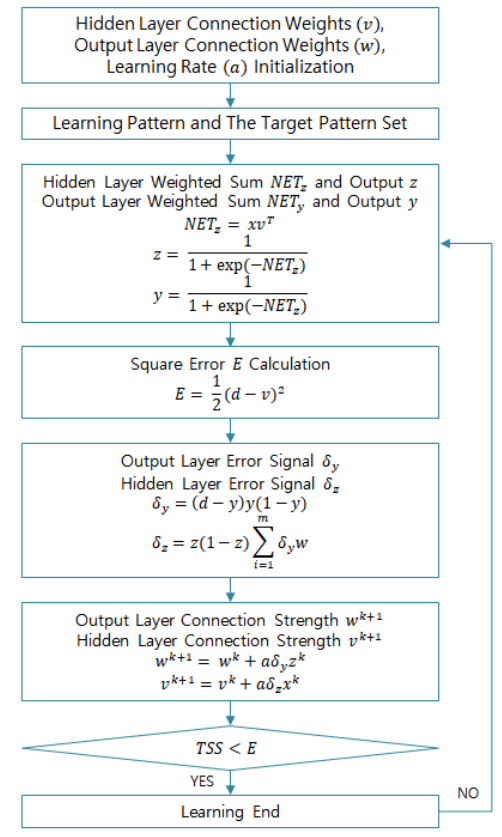

Fig. 9. The flowchart of backpropagation algorithm

(1) The input data in the neural network is applied to the input nod and the output is calculated according to the input.

(2) The error between the output according to input and desired output is calculated. 
(3) The increase and decrease of weight is decided to decrease errors.

(4) The changing degree of each weight is decided.

(5) The weight is renewed into the value decided in the above stage.

(6) Stages 1 through 5 should be repeated until the errors in all the learning data decrease to an appropriate level.

The algorithm proposed in this paper is constituted as follows, and Table $\mathbf{3}$ is its flowchart.

Table 3. The flowchart of the proposed algorithm

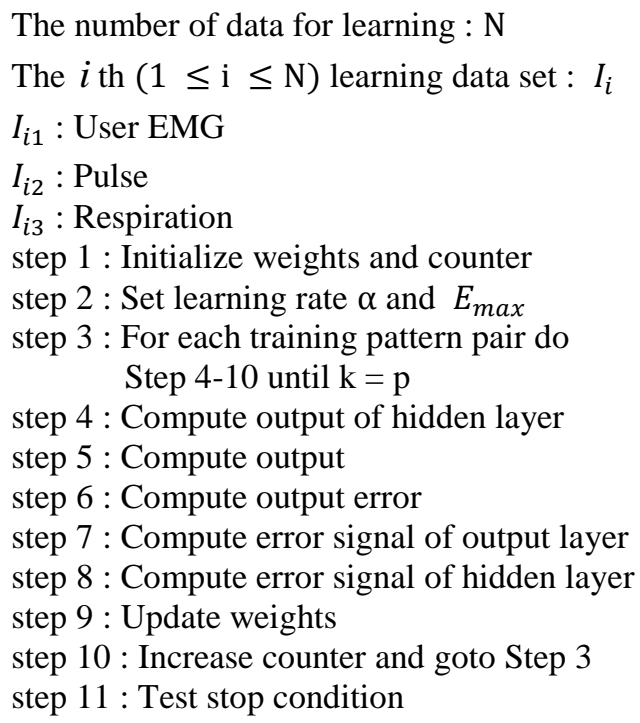

Shown below is the neural network created based on the three input data.

(1) The number of nodes in the input layer should be 3 , the number of each data item.

(2) The output layer has 10 nodes for the classification of the torque values. If the first node is selected according to the weight learned through the input data, it corresponds to the torque value level 1.

(3) The number of hidden nodes is one or more. As the learning time increases according to the number of hidden layers, an appropriate number of hidden layers is selected.

(4) The maximum and minimum values are obtained from the input data and then normalized.

Fig. 10 shows a part of the proposed backpropagation algorithm. 


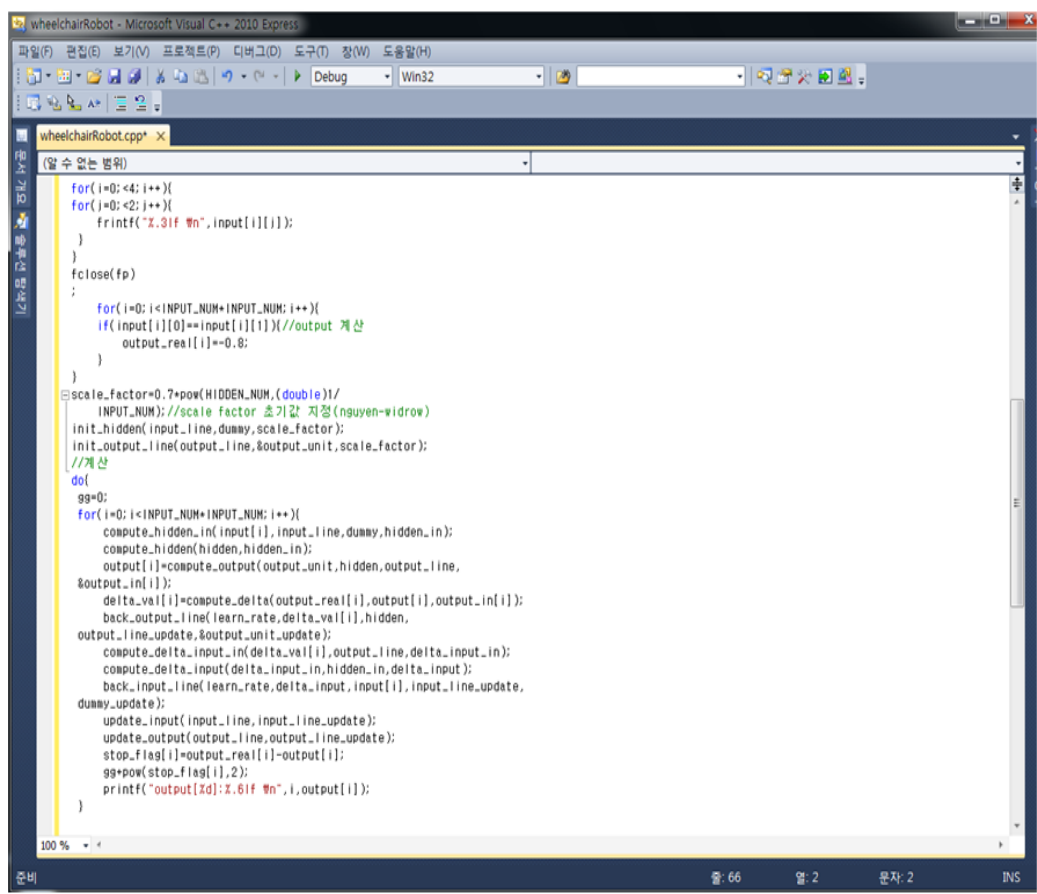

Fig. 10. The proposed backpropagation algorithm

\section{System Implementation Result}

\subsection{Wheelchair Vehicle System}

The wheelchair vehicle system implemented in this paper weighs less than $110 \mathrm{~kg}$ using a modular design and aluminum steel material to reduce weight and meet the existing wheelchair standards. It is designed to be able to travel in eight directions to provide smooth movement to the user.

To realize the upper/lower limb rehabilitation training functions, the upper/lower limb rehabilitation vehicle system, which comprises the upper limb rehabilitation with two degree-of-freedom and the lower limb rehabilitation with one degree-of-freedom, is implemented as a single unit integrated with the wheelchair, and a neural network controller is implemented to enable intelligent torque control according to user's EMG and biometric information. A touchscreen interface using a tablet PC is implemented for a user-friendly interface. In other words, the movement, upper/lower limb rehabilitation, standing exercise, and user monitoring can be performed in the integrated single-unit system. Fig. 11 shows the intelligent upper/lower limb rehabilitation wheelchair vehicle system implemented in this paper, and Table 4 shows its manufacture specifications. 


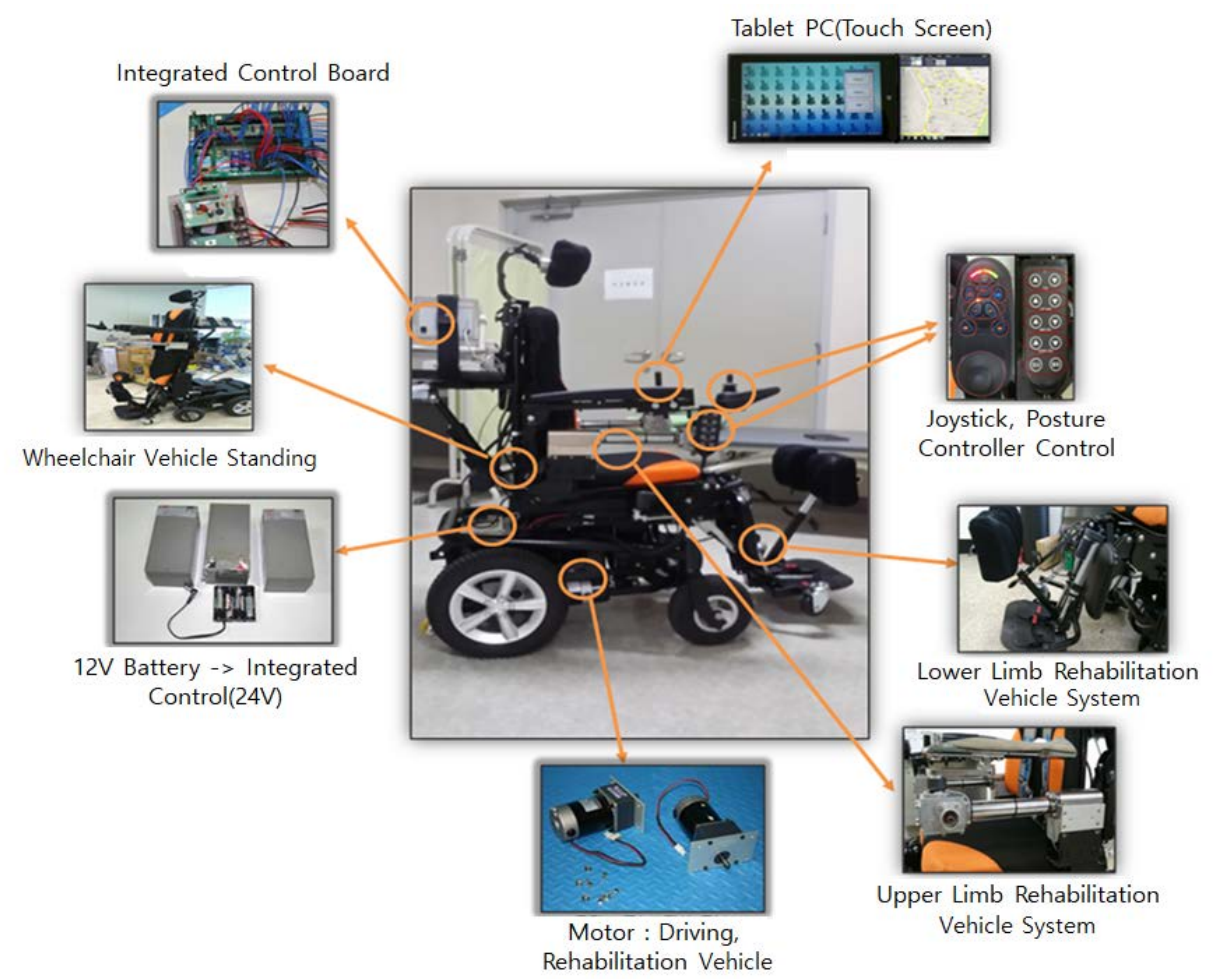

Fig. 11. The implementation result of the intelligent upper/lower limb rehabilitation wheelchair vehicle system

Table 4. The Manufacturer specifications of the wheelchair vehicle system

\begin{tabular}{|c|c|}
\hline Item & Manufacturer Specifications \\
\hline \hline Dimensions & $1200 \times 650 \times 1100 \mathrm{~mm}^{3}$ \\
\hline Total Standing Height & $170 \mathrm{~cm}$ \\
\hline SEAT $\left(\mathrm{W} * \mathrm{D}^{*} \mathrm{H}\right) \mathrm{cm}$ & $20 \mathrm{~cm}$ \\
\hline Seat Elevation Maximum Height & 9 (width)+45(depth)+55(height)cm \\
\hline Front Wheel/Rear Wheel & $120 \mathrm{~kg}$ \\
\hline Maximum Load & P\&G \\
\hline Controller & $24 \mathrm{~V} / 450 \mathrm{~W} \times 2$ \\
\hline Motor & $12 \mathrm{~V} / 55 \mathrm{AH} \times 2$ \\
\hline Battery & $230 \times 138 \times 226 \times 2$ \\
\hline Battery Dimensions & $24 \mathrm{~V} / 6 \mathrm{~A}$ \\
\hline Charger & $8-10 \mathrm{~h}$ \\
\hline Charging Time & $90^{\circ}-150^{\circ}$ \\
\hline Backrest Adjustment Angle & $0^{\circ}-90^{\circ}$ \\
\hline Footrest Adjustment Angle & $110 \mathrm{~kg}$ \\
\hline Total Weight & $35-40 \mathrm{~km}$ \\
\hline Travel Range & $11^{\circ}$ \\
\hline Maximum Back Plate Angle & $8-10 \mathrm{~km} / \mathrm{h}$ \\
\hline Maximum Speed & \\
\hline & \\
\hline
\end{tabular}


In addition, if the rehabilitation exercise is performed only in a sitting posture on a wheelchair, the exercise is mainly concentrated on the leg joints, resulting in limited rehabilitation exercises. Therefore, the standing exercise function is implemented in the proposed system to extend the range of the rehabilitation exercises. Improved accessibility is achieved through the implementation of the standing function that can actively support the lower limb rehabilitation exercise. It was designed to stand only up to $85^{\circ}$ from the ground so that the user can maintain a comfortable posture during the standing exercise, and the implementation allows the adjustment of the backrest and footrest for the user's convenience. Fig. 12 shows the result of the upper/lower limb rehabilitation wheelchair vehicle system with the standing function being implemented.

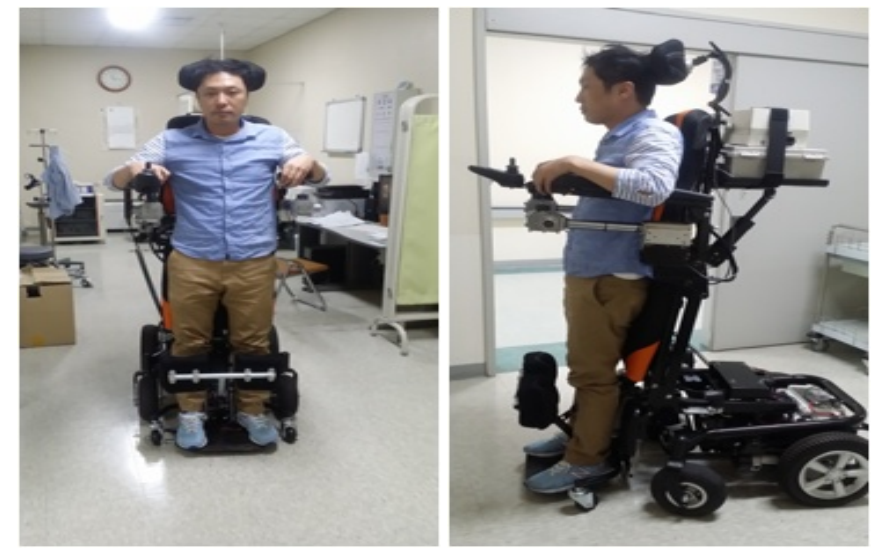

Fig. 12. The implementation result of standing of the upper/lower limb rehabilitation wheelchair vehicle system

\subsection{Upper/Lower Limb Rehabilitation Vehicle System}

The upper limb rehabilitation vehicle system in this paper is implemented in two degree-of-freedom to allow the rehabilitation of the shoulder joint and the elbow joint through rotational motion and shares a common motor/reducer with the lower limb rehabilitation vehicle system to realize integrated control. Fig. 13 shows the implementation results of the upper limb rehabilitation vehicle system developed in this paper, and Table 5 lists its manufacture specifications.

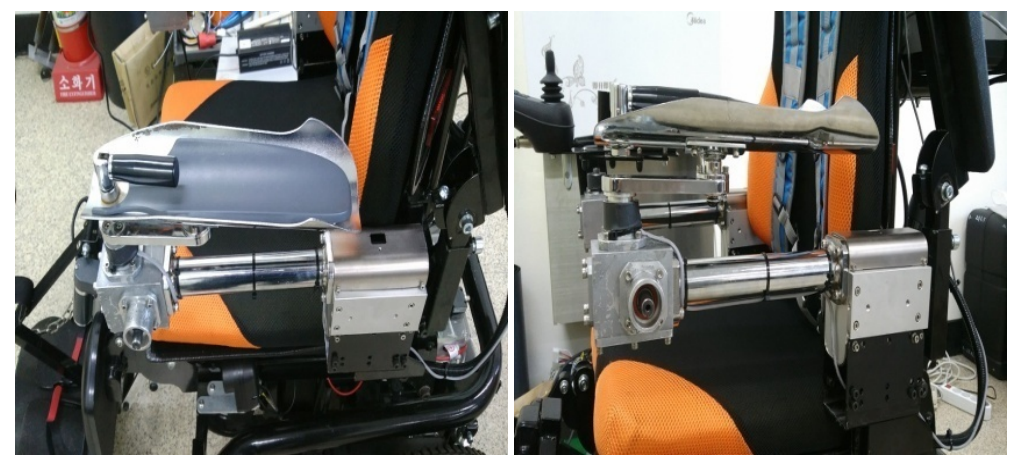

Fig. 13. The implementation results of the upper limb rehabilitation vehicle system 
Table 5. The Manufacturer specifications of the upper limb rehabilitation vehicle system

\begin{tabular}{|c|c|}
\hline Item & Manufacturer Specifications \\
\hline \hline Degrees of Freedom & 2 \\
\hline Joint Angle Tolerance & $0.5^{\circ}$ \\
\hline Weight & $3.45 \mathrm{~kg}$ \\
\hline Motor & DC 24V 170W, Max 9,120RPM \\
\hline Torque Rating & Max 12.9 Nm \\
\hline Reduction Ratio & $90: 1$ \\
\hline
\end{tabular}

The lower limb rehabilitation vehicle system has a total of two degree-of-freedom on both legs, one per leg to allow the exercise of the elbow and the knee through up-down movement, and its implementation allows step-wise rehabilitation exercises by controlling the torque output power according to the rating, just as in the upper limb rehabilitation vehicle system. Additionally, the system can adjust the distance between the wheelchair seat and the lower limb rehabilitation vehicle system and realize an integrated control by sharing the common motor/reducer with the upper limb rehabilitation vehicle system. Fig. 14 shows the implementation result of the lower limb rehabilitation vehicle system developed in this paper, and Table 6 lists its manufacture specifications.
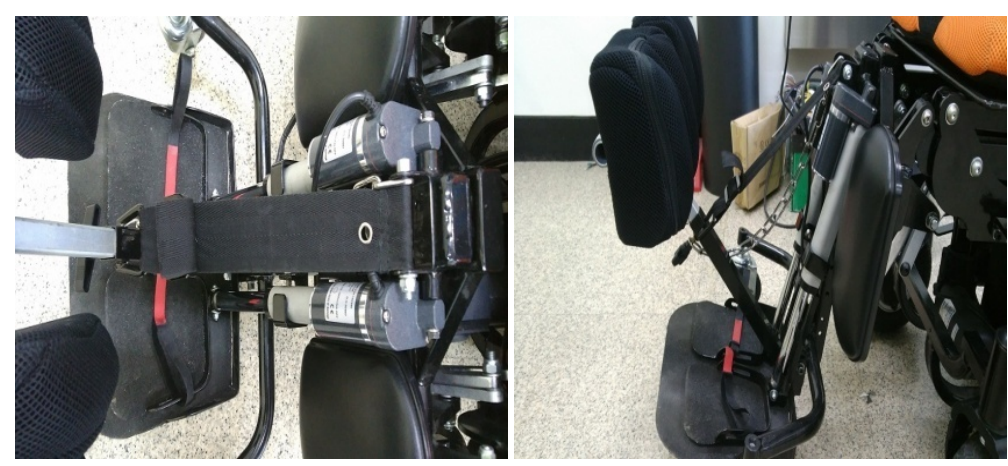

Fig. 14. The implementation results of the lower limb rehabilitation vehicle system

Table 6. The Manufacturer specifications of the lower limb rehabilitation vehicle system

\begin{tabular}{|c|c|}
\hline Item & Manufacturer Specifications \\
\hline \hline Degrees of Freedom & 1 \\
\hline Joint Angle Tolerance & $0.5^{\circ}$ \\
\hline Weight & $5.43 \mathrm{~kg}$ \\
\hline Motor & DC 24V 170W, Max 9,120RPM \\
\hline Torque Rating & Max 36.7 Nm \\
\hline Reduction Ratio & $270: 1$ \\
\hline
\end{tabular}

\subsection{User Interface}

The interface is configured to utilize the touchscreen of the tablet PC and the inter-linkage with a smart phone. The tablet PC of Intel ATOM Z3740 is used with Windows 8 as its operating system and Bluetooth 4.0 as its communication method. 
The implemented user interface measures the user's biosignals (EMG, pulse, and respiration), analyzes the sensed biometric data in real time, and monitors the result of biosignal change according to rehabilitation. Fig. 15 shows the DB and module of the biometric analysis system, and Fig. 16 shows the implementation result of the user interface of the biometric analysis system.

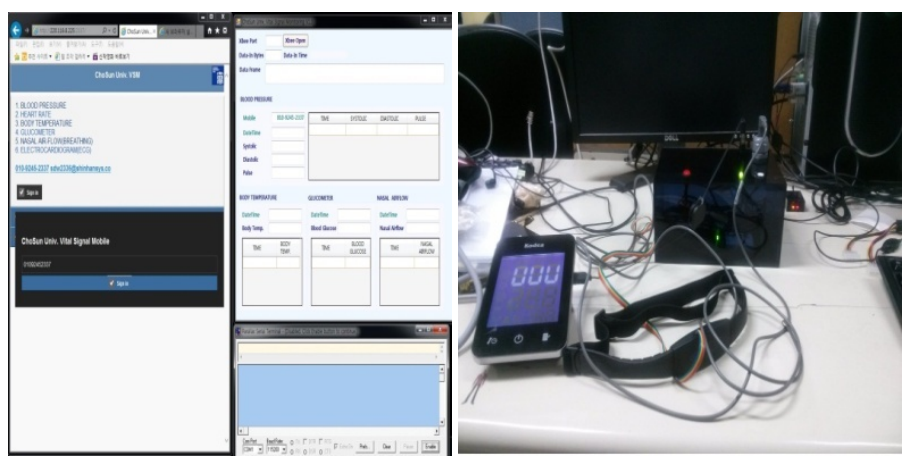

Fig. 15. The DB and module of the biometric analysis system
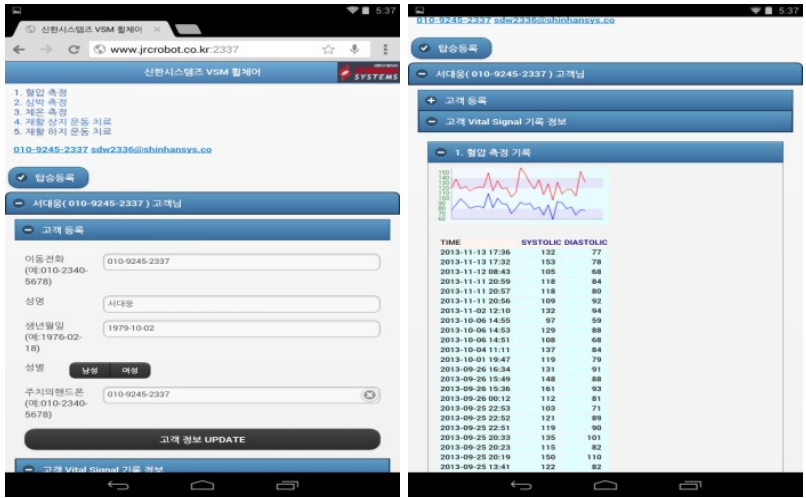

Fig. 16. The implementation result of the user interface of the biometric analysis system

In addition, the driving mode and the rehabilitation mode are configured in the user interface, as shown in Fig. 17. The driving mode is related to the wheelchair vehicle system, in which the system can check the user's position and driving speed using the GPS recognition program. The tilt angle displayed by the tilt sensor help the user directly check the possibility of standing exercise and control whether to stand or not. The implementation allows the user to check the remaining battery capacity and possible distance for the intelligent upper/lower limb rehabilitation wheelchair vehicle to travel on the basis of time. In the case of the rehabilitation mode, the upper/lower limb rehabilitation exercises can be intelligently performed according to the user's EMG and biosignals through the interface related to the upper/lower limb rehabilitation exercise, in which the driving mode of the wheelchair is not activated.

Moreover, the upper limb rehabilitation exercise is implemented for the user to be able to directly select the directions of movement such as forward/backward and left/right, and the intensity and duration of the exercise. The lower limb rehabilitation exercise is implemented for the user to select the limbs (left/both/right) and the intensity and duration of the excises. 
Fig. 18 shows the execution result of the driving mode and the rehabilitation mode of the user interface.

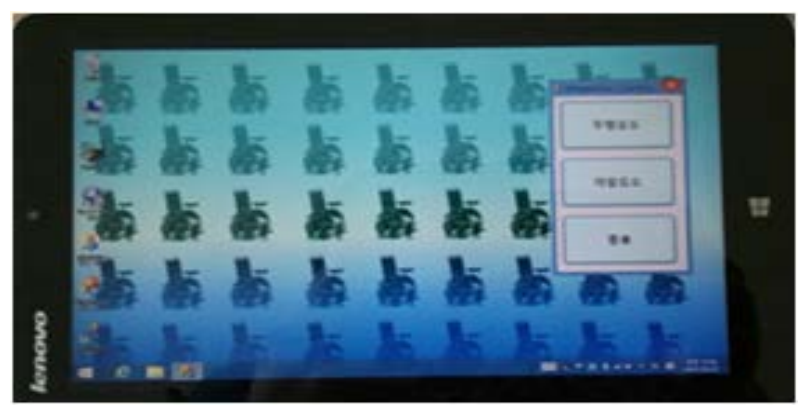

Fig. 17. The implementation result of the user interface
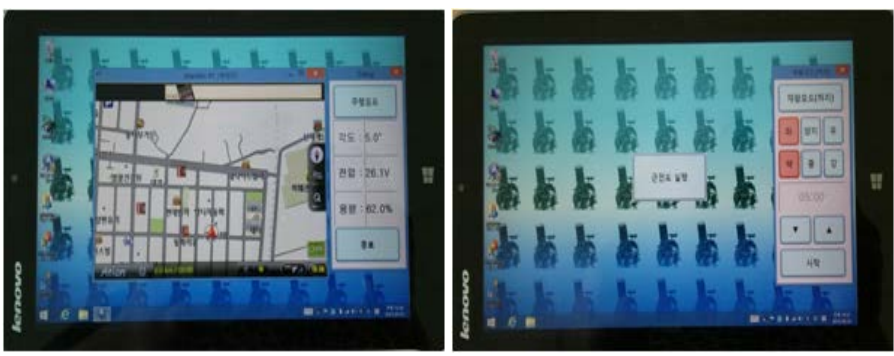

Fig. 18. The execution result of the navigation mode and the rehabilitation mode of the user interface

\section{Performance Evaluation}

To test the performance of the implemented system, each user's EMG and biosignal are measured and used for the learning of the neural network, and user-tailored rehabilitation exercise is performed by controlling torque output according to the state of the user's EMG and biosignal.

As the input variables to classify the muscle strength and biosignal, the values of user's EMG, pulse, and respiration are applied to the neural network and implemented to the control of the torque output based on the classified levels, as shown in Table 7.

Table 7. The torque output based on the classified levels according to muscle strength and biosignal

\begin{tabular}{|c|c|c|c|c|c|c|c|}
\hline $\begin{array}{c}\text { Classified } \\
\text { Level }\end{array}$ & \multicolumn{3}{|c|}{$\begin{array}{c}\text { Muscle Strength } \\
\text { Rating } \\
\end{array}$} & Pulse & Respiration & \multirow{6}{*}{\multicolumn{2}{|c|}{$\begin{array}{c}\text { Torque Output Value } \\
\text { Passive Movement } \\
\text { Minimum: } 10 \% \\
\text { Maximum: less than } 50 \% \\
\text { (Average: } 25 \% \text { ) }\end{array}$}} \\
\hline 1 & 0 & Zero & $\mathrm{Z}$ & 60-65 & $12-14$ & & \\
\hline 2 & 1 & Trace & $\mathrm{T}$ & $65-70$ & $14-16$ & & \\
\hline 3 & $2-$ & Poor- & $\mathrm{P}-$ & $70-75$ & $16-18$ & & \\
\hline 4 & 2 & Poor & $\mathrm{P}$ & $75-80$ & $18-20$ & & \\
\hline 5 & $2+$ & Poor+ & $\mathrm{P}+$ & $80-85$ & $20-22$ & & \\
\hline 6 & 3- & Fair- & F- & $85-95$ & $22-24$ & $\begin{array}{c}\text { Active } \\
\text { Supporting } \\
\text { Movement }\end{array}$ & $\begin{array}{l}\text { Minimum : 50\%; } \\
\text { Maximum : } 75 \%\end{array}$ \\
\hline 7 & 3 & Fair & $\mathrm{F}$ & 95-105 & $24-26$ & $\begin{array}{c}\text { Active } \\
\text { Supporting } \\
\text { Movement }\end{array}$ & $\begin{array}{l}\text { Minimum : 50\%; } \\
\text { Maximum : } 75 \%\end{array}$ \\
\hline
\end{tabular}




\begin{tabular}{|c|c|c|c|c|c|c|c|}
\hline 8 & $3+$ & Fair + & $\mathrm{F}+$ & $105-115$ & $26-28$ & $\begin{array}{c}\text { Active } \\
\text { Supporting } \\
\text { Movement }\end{array}$ & $\begin{array}{c}\text { Minimum : 50\%; } \\
\text { Maximum : 75\% }\end{array}$ \\
\hline 9 & 4 & Good & G & $115-125$ & $28-30$ & $\begin{array}{c}\text { Active } \\
\text { Movement }\end{array}$ & $\begin{array}{c}\text { Minimum : 75\%; } \\
\text { Maximum : } \\
100 \%\end{array}$ \\
\hline 10 & 5 & Normal & N & Over 125 & $30-32$ & $\begin{array}{c}\text { Resistance } \\
\text { Movement }\end{array}$ & $100 \%$ \\
\hline
\end{tabular}

In general, the needle electrode method is used to measure an accurate electromyographic signal in a specific muscle. In this paper, however, the surface electrode method, a comparatively easy method, is used to avoid the discomfort to inject a needle into the examinee's body. In collecting the electromyographic signal of upper/lower limbs, a 4-channel electromyographic amplifier (LMX3204, Laxtha, Korea) is used with the setting of Amplifier gain 700, Band-pass filter frequency $8-480 \mathrm{~Hz}$, and Sampling frequency $1000 \mathrm{~Hz}$.

The output value for torque control is set into 6 steps according to the torque output categorization; $0.005,0.010,0.020,0.055,0.070,0.100 \mathrm{~N} . \mathrm{m}$. The reason the highest torque value is fixed to $0.100 \mathrm{~N} . \mathrm{m}$ is that the degree, high enough for an ordinary person with a normal physique doing rehabilitation exercise, is too much to be applied to a patient.

Fig. 19 indicates the results of upper limb rehabilitation exercise and Fig. 20 those of lower limb rehabilitation exercise.

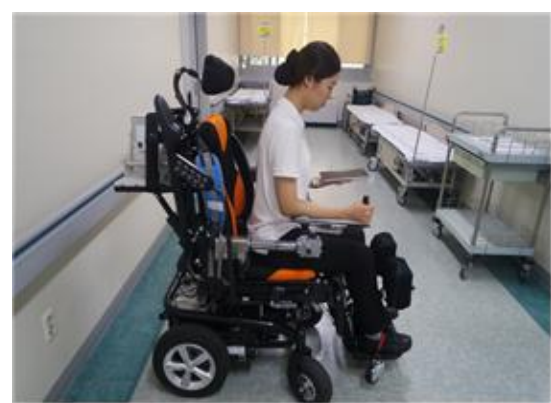

(a) Elbow $\left(90^{\circ}\right)$

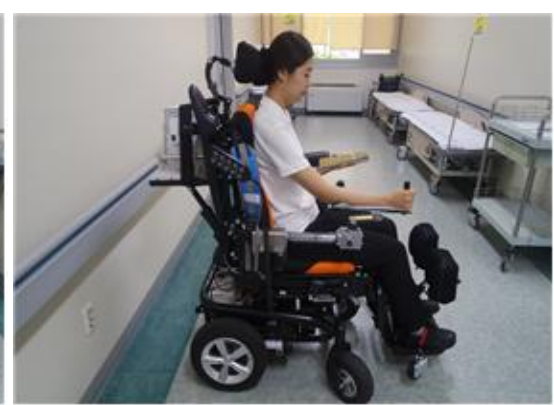

(b) Elbow $\left(45^{\circ}\right)$

Fig. 19. The result of upper limb rehabilitation exercise

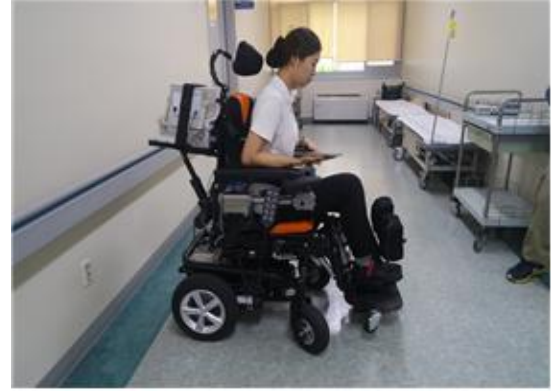

(a) Hip joint $\left(90^{\circ}\right)$, Knee joint $\left(90^{\circ}\right)$

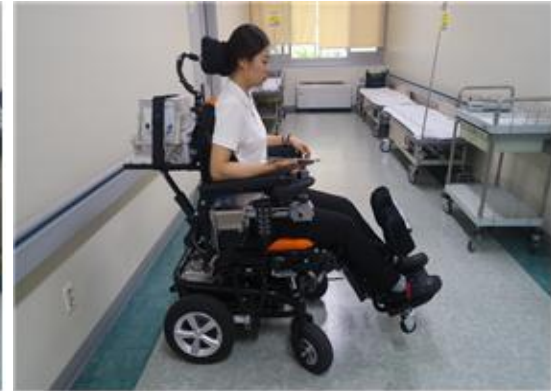

(b) Hip joint $\left(90^{\circ}\right)$, Knee joint $\left(45^{\circ}\right)$ 


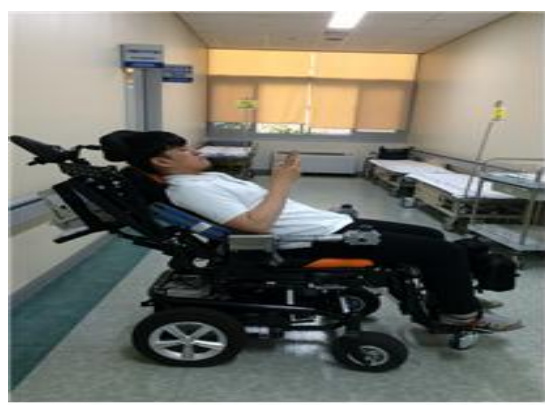

(a) Hip joint $\left(45^{\circ}\right)$, Knee joint $\left(90^{\circ}\right)$

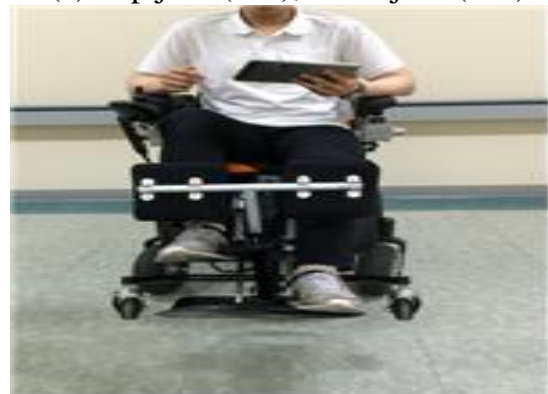

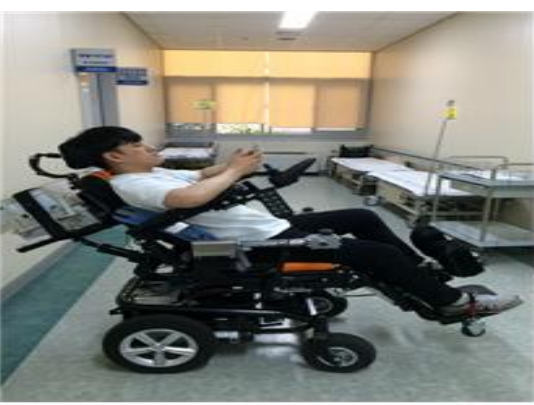

(b) Hip joint $\left(45^{\circ}\right)$, Knee joint $\left(45^{\circ}\right)$

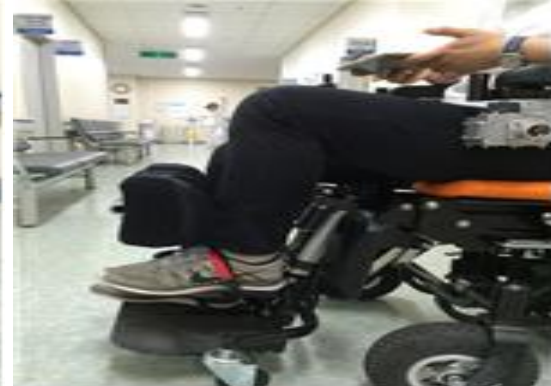

Fig. 20. The result of lower limb rehabilitation exercise

Fig. 21 is the results of measurement and execution of periodically measured EMG and biometric data (pulse and respiration) during upper and lower rehabilitation exercise, which can be shown on the user interface implemented on the tablet PC touchscreen of the wheelchair vehicle system. The implemented user interface outputs the user's biodata information such as EMG, pulse, and respiration value in real time.
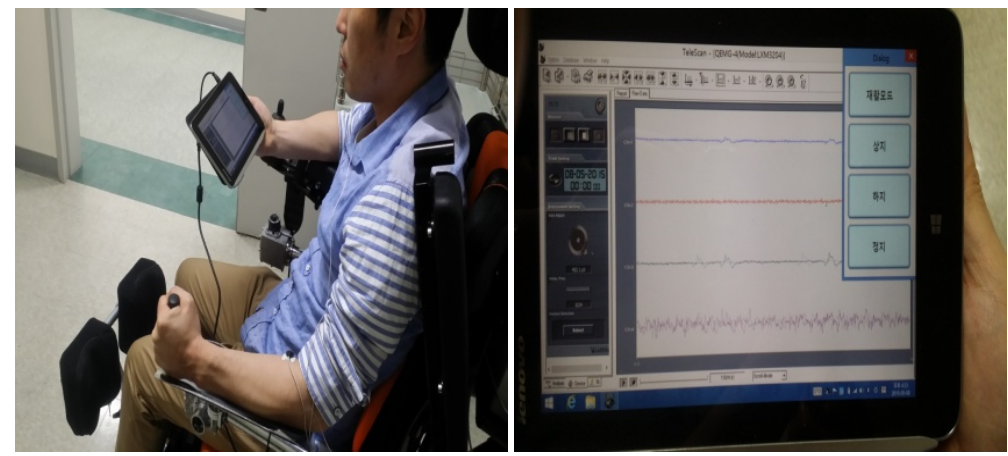

Fig. 21. The result of measurement and execution of the biometric data

To test the performance of the proposed algorithm, 200 biometric data (EMG, pulse, and respiration) are periodically obtained (every $1 \mathrm{~min}$ ) while the examinee is performing 10 rehabilitation exercise sessions for $30 \mathrm{~min}$, was analyzed after learning the neural network algorithm. In this paper, using the user's EMG, pulse, and respiration as the input, and setting the target error rate to 0.001 and the number of learning to 1500, a total of 200 biomedical data are used for the learning of the neural network based on the backpropagation algorithm, which 
comprised 3 input layers, 15 hidden layers, and 1 output layer. As a result, 1388 times of learning are performed with the error rate of 0.0093 .

Ten-fold cross-validation is performed to minimize the influence of the training data on the experimental results and to secure reliability. Table 8 shows the analysis accuracy (unit: \%) of the system. The average accuracy of the torque output classification according to the user's EMG and biosignal during the rehabilitation exercise of the examinee is $87.8 \%$.

Table 8. The analysis accuracy (unit: \%) of the system

\begin{tabular}{|c|c|}
\hline Fold Number & Torque Output Analysis Accuracy \\
\hline 1 & 89.1 \\
\hline 2 & 86.3 \\
\hline 3 & 87.5 \\
\hline 4 & 86.5 \\
\hline 5 & 89.5 \\
\hline 6 & 90.3 \\
\hline 7 & 89.8 \\
\hline 8 & 87.1 \\
\hline 9 & 86.3 \\
\hline 10 & 85.7 \\
\hline
\end{tabular}

To analyze the tracking performance of upper/lower limb rehabilitation exercises, the examinee performs the upper/lower limb rehabilitation exercise while sitting on the wheelchair and the standing exercise while the wheelchair is not in motion. In this case, the upper limb, the lower limb, and the standing exercises are done independently, and the range of motion of the upper/lower limb rehabilitation vehicle and the standing was $0^{\circ}$ to $90^{\circ}$, and errors in the joint were measured after each exercise was repeated 100 times. The angle of each joint segment is obtained from the relative angles of the two joint segments after measuring the positional coordinates for each joint during the rehabilitation exercise of the subject.

Since the experiment uses random data reflecting the real-world situation, which does not have a linear relation, the error rate should be measured. In this experiment, root-mean-square error(MRSE) is used to measure the error rate, as shown in Equation 1.

$$
R M S E=\sqrt{\frac{1}{n} \sum_{i=1}^{n}\left(y_{i}-y_{i}^{*}\right)^{2}}
$$

In order to examine the tracking performance of the joint angle of the upper limbs, the reference value calculated after the measurement of the angular displacements of the examinee's shoulder and elbow and the angular displacement output from the encoder after the upper limbs rehabilitation exercises are measured. 


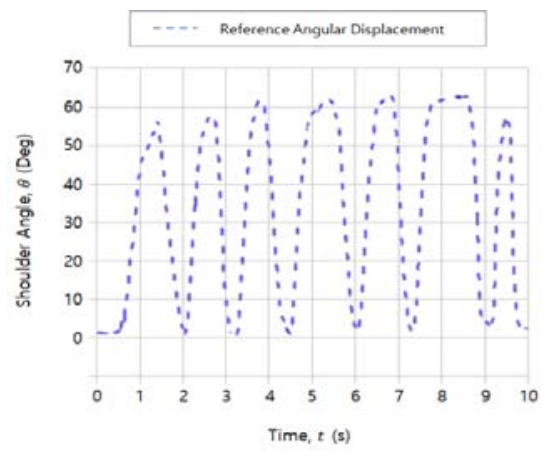

(a) Reference Angular Displacement

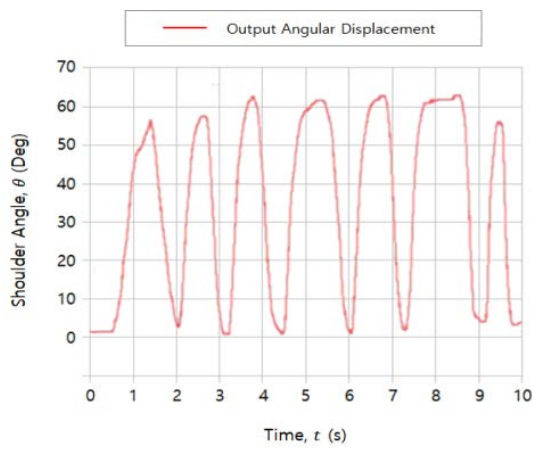

(b) Output Angular Displacement

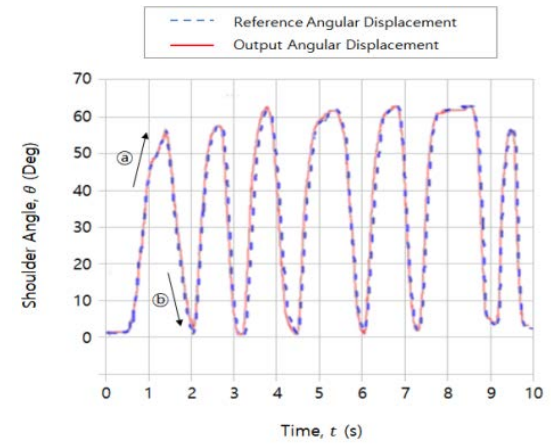

(c) Reference Angular Displacement \& Output Angular Displacement

Fig. 22. The experimental evaluation of Shoulder flexion/extension tracking performance

Fig. 22 indicates the results of the tracking performance examination for the flexion/extension exercises of the shoulder joints. (a) indicates the reference angular displacement, (b) the angular displacement output from the encoder during the upper limbs rehabilitation exercises, and (c) a graph comparing the reference angular displacement and output angular displacement. (a) indicates the flexion exercises of the shoulder and (b) extension exercises. The examination result of the shoulder exercises shows $93.07 \%$ of concordance rate of movement tracking with the average error of $2.61^{\circ}$.

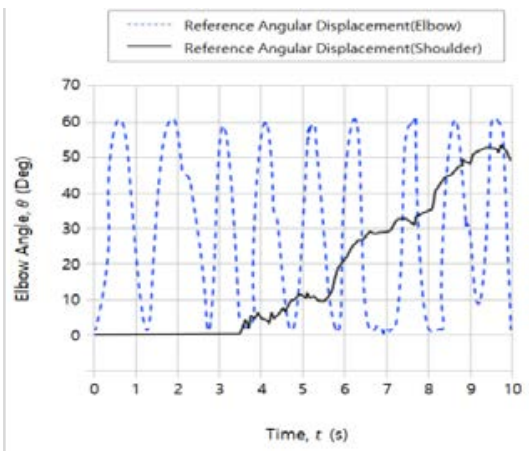

(a) Reference Angular Displacement

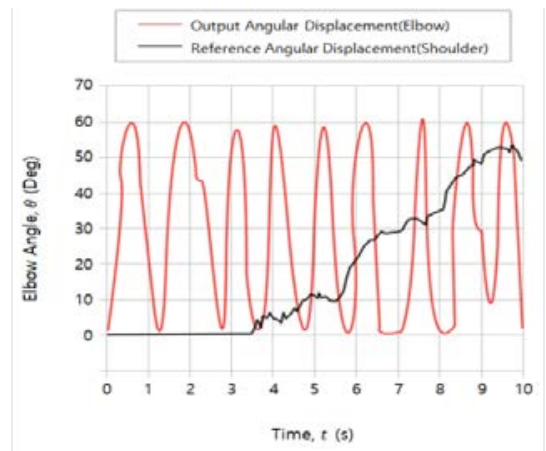

(b) Output Angular Displacement 


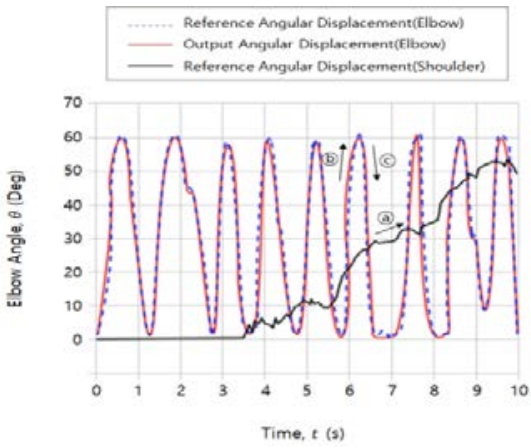

(c) Reference Angular Displacement \& Output Angular Displacement

Fig. 23. The experimental evaluation of elbow flexion/extension tracking performance

As the flexion/extension, which belongs to the elbow movements, appears according to the external rotation of the shoulder movement, the concordance rate of the elbow is analyzed as shown in Fig. 23. (a) in Fig. 23 indicates the standard angular displacement of the external rotation of the shoulder and the elbow, (b) the angular displacement of the elbow output from the encoder during the upper limbs rehabilitation exercises, and (c) a graph comparing the reference angular displacement and output angular displacement. The result (a) indicates the external rotation of the shoulder, (b) the flexion of the elbow, and (c) the extension of the elbow. The examination result of the elbow movement shows $95.09 \%$ of concordance rate of movement tracking with the average error of $2.43^{\circ}$.

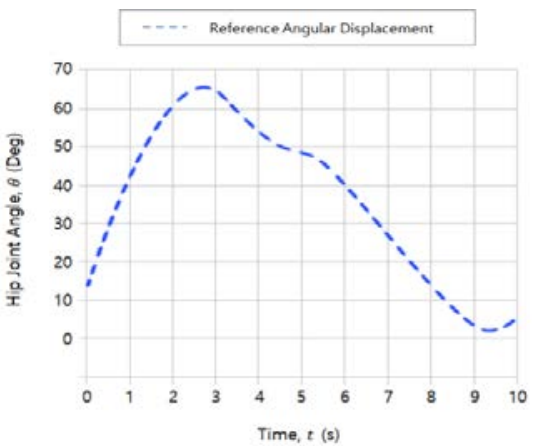

(a) Reference Angular Displacement

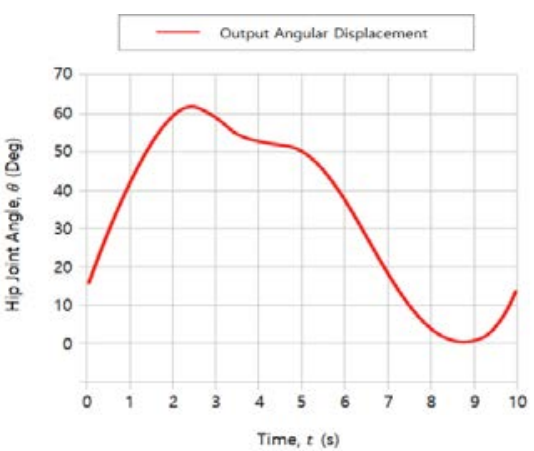

(b) Output Angular Displacement

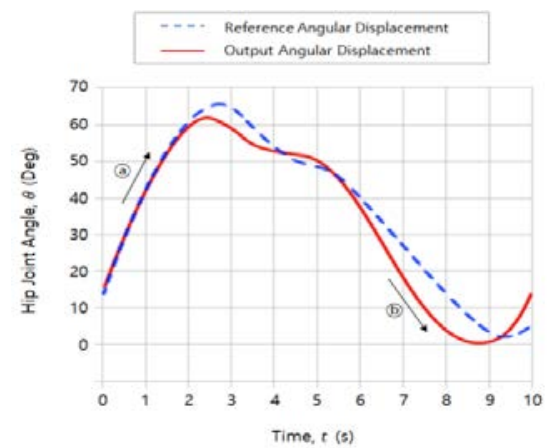

(c) Reference Angular Displacement \& Output Angular Displacement

Fig. 24. The experimental evaluation of hip joint flexion/extension tracking performance 
In the lower limb joint angle examination, the reference value calculated after the measurement of the angular displacements of hip joint and knee joint and the angular displacement output from the encoder after the lower limbs rehabilitation exercises are measured. Fig. 24 indicates the examination results of the flexion/extension tracking performance of hip joint. (a) shows the standard angular displacement of the hip joint, (b) the angular displacement output from the encoder during the lower limbs rehabilitation movement, and (c) a graph comparing the reference angular displacement and output angular displacement. (a) indicates the flexion exercises of the hip joint and (b) extension exercises. The examination result of the hip joint movement shows $93.32 \%$ of concordance rate of movement tracking with the average error of $2.59^{\circ}$.

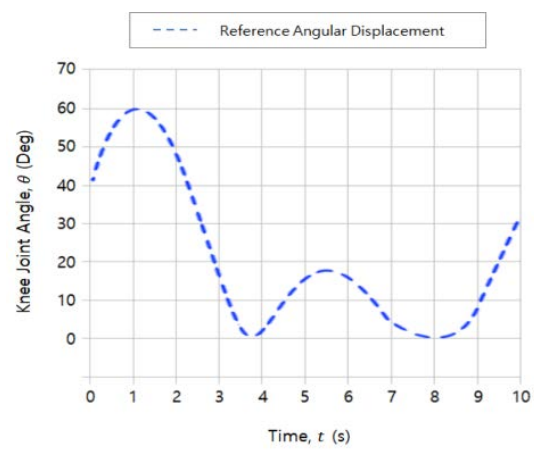

(a) Reference Angular Displacement

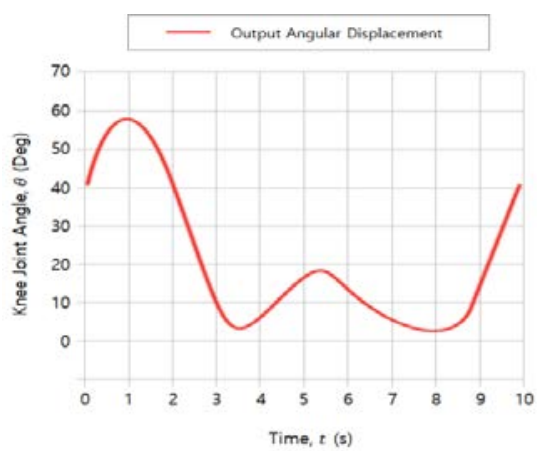

(b) Output Angular Displacement

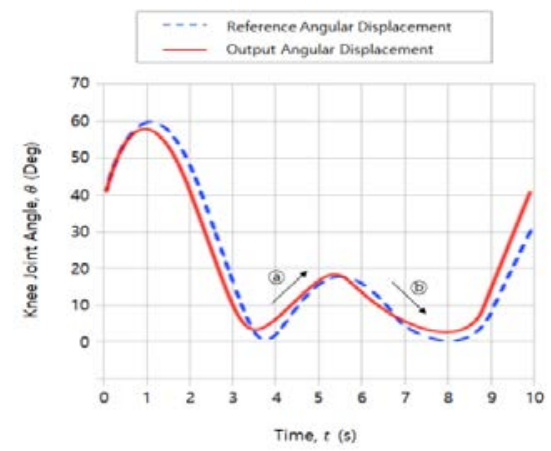

(c) Reference Angular Displacement \& Output Angular Displacement

Fig. 25. The experimental evaluation of knee joint flexion/extension tracking performance

Fig. 25 indicates the examination results of the flexion/extension tracking performance of the knee joint. (a) shows the standard angular displacement of the knee joint, (b) the angular displacement output from the encoder during the lower limbs rehabilitation exercise, (c) a graph comparing the reference angular displacement and the angular displacement output from the encoder. (a) indicates the flexion exercises of the knee joint and (b) extension exercises. The examination result of the knee joint exercise shows $95.14 \%$ of concordance rate of movement tracking with the average error of $2.43^{\circ}$.

The results of the analysis of the experiment show that the average error of the joint angle is $2.52^{\circ}$ in the upper limb rehabilitation exercise, $2.46^{\circ}$ in the lower limb rehabilitation exercise, and $2.14^{\circ}$ in the standing exercise, which demonstrate enough tracking performance for the execution of the rehabilitation exercise. Fig. 26 shows the result of performance evaluation. 


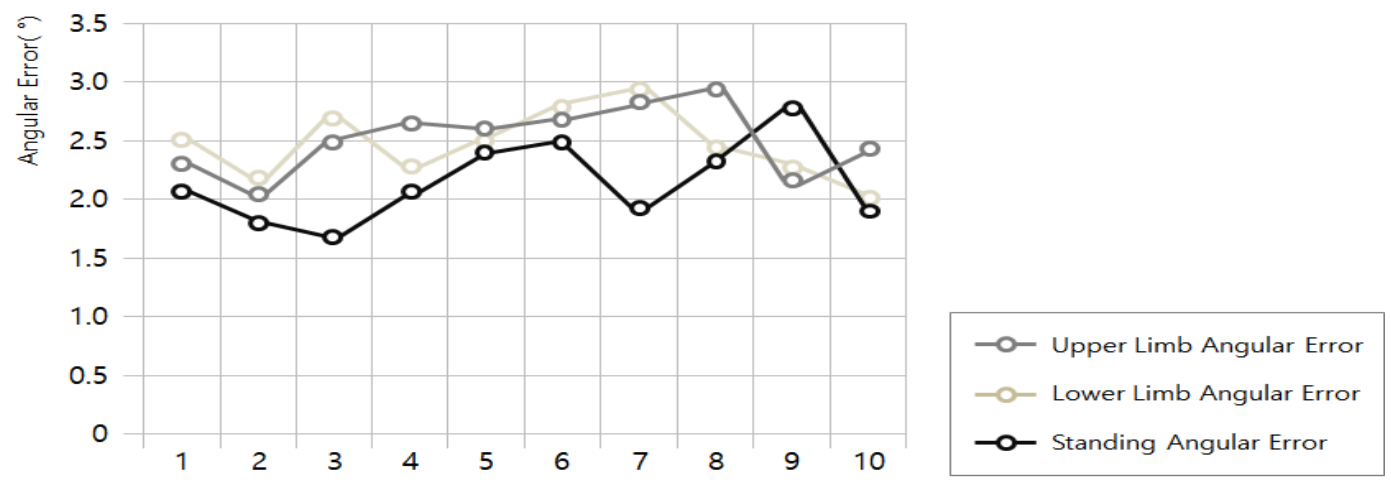

Fig. 26. The tracking performance evaluation results

\section{Conclusion}

The modern society of today has seen the dramatic increase in geriatric or brain-related diseases resulted from rapid industrialization and aging of people. In addition, the secondary diseases such as physical motion disorder and the malfunctions of cognitive ability caused by diseases and unexpected accidents are on the increase. Among diverse rehabilitation programs conducted to recover and retain the motion ability of such patients, the therapeutic exercise is the most representative. In therapeutic exercise, it is most important to set a proper exercise intensity according to the state of a patient.

That is the diagnosis and evaluation of a patient's state of muscular strength and personal difference in it should be followed by subsequent rehabilitation exercise. For too much intensity in exercise may endanger the patients and too weak intensity may not secure expected effectiveness in treatment. Most of therapeutic exercises presently conducted in hospitals are based on the treatment plans of physical therapists. Such therapy plans are conducted by physical therapists according to the commission of the doctor who listened to the patients subject intention, which may cause the discrepancies between the state of a patient and the motion load, resulting in ineffective therapeutic exercise. Therefore, it is necessary that a new system be developed to make up such demerits and proceed with more effective rehabilitation program.

The existing researches are focused on the development of a walking assistance vehicle system in the form of a wheelchair to improve locomotor function as a first limit of the patients with gait disturbance. As the walking assistance vehicle system has been developed for the purpose of the patients' transit convenience, it has no fundamental consideration for the function of rehabilitating training. Especially, the wearable exoskeleton vehicle as a representative of the walking assistance vehicle system is accompanied with the stability problem in posture balance while assisting walking, and, due to the limits of body-exoskeleton alignment, it requires excessive time in wearing and adjusting and causes much difficulty in long-time wearing and walking.

Also the research and development of rehabilitation vehicles which can accurately control the range of joint mobility just like a treadmill are actively proceeded. However, such vehicles may not be applied on a real time basis to the old and the disabled, who are required to prevent the regression of muscular-skeleton functions through persistent rehabilitation training in daily lives, and too much expense also decreases their accessibilities to treatment. 
Therefore, in this paper, in order to overcome all the limitations in the systems so far mentioned, we propose and embody a rehabilitation vehicle system in a new and complex concept, which enables the locomotion and rehabilitation in daily activities by combining the wheelchair vehicle system for locomotion function and standing exercises with the upper/lower limb rehabilitation vehicle system, and attempt to verify its applicability.

To enable the intelligent upper/lower limb rehabilitation exercise of the system proposed in this paper, the user's EMG and biosignals (pulse and respiration) are measured and used for neural network learning and controlling the torque output according to the user's EMG and biosignal.

In order to evaluate the capability of supposed algorithm, the examinee's biosignals are obtained and analyzed after neural network learning, and, to minimize the affection from the learning data on the result of experiment 10 -fold cross-validation is conducted. As a result, the user's electromyogram and biosignals(pulse, respiration) during the examinee's rehabilitation activities are learned through neural network algorithm categorized according to the level of torque output based on strength and biosignals. The average accuracy of the categorized data is $\mathbf{8 7 . 8 \%}$. Also the analysis of the tracking performance of upper/lower limbs rehabilitation and standing exercise indicates that the average case error of joint angle during the upper limb rehabilitation exercise is $2.52^{\circ}, 2.46^{\circ}$ in lower limb exercise, and $2.14^{\circ}$ in standing exercise, which demonstrate enough tracking performance for the rehabilitation exercises.

It is expected that the proposed system will assure the user's mobility, provide sustained rehabilitation exercises in daily life and user-tailored rehabilitation using the user's EMG and biometric information, and help improve the user's will to rehabilitate and quality of life by monitoring the biometric information and rehabilitation information.

In the future, the performance of the proposed system will continue to be improved through further researches on the functions of the proposed algorithm, diverse intelligent top and bottom motion algorithms, and the rehabilitative contents as well as ceaseless clinical evaluation of the intelligent upper and lower wheelchair vehicle system proposed in this paper.

\section{References}

[1] M. Bang, J. Kim, E. Kim, W. Song, J. Kim and D. Cho, "Current Status and Development Strategy of Rehabilitation Robot Intermediary Research,” National Rehabilitation Center, September, 2012.

[2] B. Li, G. Li, Y. Sun, G. Jiang, J. Kong and D. Jiang, “A review of rehabilitation robot,” in Proc. of 32nd Youth Academic Annual Conference of Chinese Association of Automation (YAC), pp. 907-911, May, 2017. Article (CrossRef Link).

[3] S. Katsura and K. Ohnishi, "Semiautonomous Wheelchair Based on quarry of environmental information,” IEEE Transactions on Industria Electronics Society, Vol. 53, No. 4. pp. 1373-1382, 2006. Article (CrossRef Link).

[4] R. Simpson, E. Loprestil, S. Hayashi, I. Nourbakhsh and D. Miller, "The Smart Wheelchair Component System,” Journal of Rehabilitation Research and Development, Vol. 41, No. 3B, pp. 429-442, 2004. Article (CrossRef Link).

[5] K. Wang, L. Zhang, B. Luan, H. Tung, Q. Liu, J. Wei, M. Sun and Z. Mao, "Brain-computer interface combining eye saccade two-electrode EEG signals and voice cues to improve the maneuverability of wheelchair," in Proc. of 2017 International Conference on Rehabilitation Robotics (ICORR), pp. 1073-1078, July, 2017. Article (CrossRef Link).

[6] Z. Su, X. Xu, J. Ding and W. Lu, "Intelligent wheelchair control system based on BCI and the image display of EEG," in Proc. of Advanced Information Management, Communicates, Electronic and Automation Control Conference (IMCEC), 2016 IEEE, pp. 1350-1354, October, 
2016. Article (CrossRef Link).

[7] K. Kim and S. Lee, "Towards an EEG-based intelligent wheelchair driving system with vibro-tactile stimuli," in Proc. of 2016 IEEE International Conference on Systems, Man, and Cybernetics (SMC), pp. 2382-2385, October, 2016. Article (CrossRef Link).

[8] W. Song, H. Lee, J. Kim, Y. Yoon and Z. Bien, "KARES: intelligent rehabilitation robotic system for the disabled and the elderly," in Proc. of The 20th Annual International Conference of the IEEE Engineering in Medicine and Biology Society, Vol. 5, pp. 2682-2685, November, 1998. Article (CrossRef Link).

[9] Z. Bien, D. Kim, M. Chung, D. Kwon and P. Chang, "Development of a wheelchair-based rehabilitation robotic system (KARES II) with various human-robot interaction interfaces for the disabled," in Proc. of 2003 IEEE/ASME International Conference on Advanced Intelligent Mechatronics (AIM 2003), Vol. 2, pp. 902-907, July, 2003. Article (CrossRef Link).

[10] N. Hogan, H. Krebs, J. Charnnarong, P. Srikrishna and A. Sharon, "MIT-MANUS: a workstation for manual therapy and training. I," in Proc. of IEEE International Workshop on Robot and Human Communication, pp. 161-165, 1992. Article (CrossRef Link).

[11] S. Atashzar, M. Shahbazi, O. Samotus, M. Tavakoli, M. Jog and R. Patel, "Characterization of Upper-Limb Pathological Tremors: Application to Design of an Augmented Haptic Rehabilitation System,” IEEE Journal of Selected Topics in Signal Processing, Vol. 10, No. 5, pp. 888-903, 2016. Article (CrossRef Link).

[12] C. Vidrios-Serrano, I. Bonilla, F. Vigueras-Gómez and M. Mendoza, "Development of a haptic interface for motor rehabilitation therapy using augmented reality," in Proc. of 2015 37th Annual International Conference of the IEEE Engineering in Medicine and Biology Society (EMBC), pp. 1156-1159, August, 2015. Article (CrossRef Link).

[13] K. Kong, H. Moon, B. Hwang, D. Jeon and M. Tomizuka, "Impedance Compensation of SUBAR for Back-Drivable Force-Mode Actuation," in Proc. of 2009 IEEE Transactions on Robotics, Vol. 25, No. 3, pp. 512-521, May, 2009. Article (CrossRef Link).

[14] B. Hwang, H. Moon and D. Jeon, " Monitoring method of interactive torque between human and robot in exoskeleton systems," in Proc. of 2009 IEEE International Conference on Rehabilitation Robotics, pp. 283-288, June, 2009. Article (CrossRef Link).

[15] S. Jezrnik, G. Clolombo and M. Morari, "Automatic Gait-Pattern Adaptation Algorithms for Rehabilitation whit a 4-DOF Robotic Orthosis," IEEE Transactions on Robotics and Automation, Vol. 20, No. 3, pp. 574-582, June, 2004. Article (CrossRef Link).

[16] T. Sakurai and Y. Sankai, "Development of Motion Instruction System with Interactive Robot Suit HAL," in Proc. of 2009 IEEE International Conference on Robotics and Biomimetics(ROBIO), pp. 1141-1147, December, 2009. Article (CrossRef Link).

[17] J. Hidler, W. Wisman and N. Neckel, "Kinematic Trajectories while Walking within the Lokomat Robotic gait-Orthosis,” Clinical Biomechanics, Vol. 23, No. 10, pp. 1251-1259, 2008. Article (CrossRef Link).

[18] A. Zoss, H. Kazerooni and A. Chu, "Biomechanical Design of the Berkley Lower Extremity Exoskeleton(BLEEX),” IEEE/ASME Transactions on Mechatronics, Vol. 11, No. 2, pp. 128-138, April, 2006. Article (CrossRef Link).

[19] N. Hill, T. Lal, M. Schröder, T. Hinterberger, G. Widman, C. Elger, B. Schölkopf and N. Birbaumer, "Classifying Event-Related Desynchronization in EEG, ECoG and MEG signals," Lecture Notes in Computer Science, Vol. 4174, pp. 404-413, 2006. Article (CrossRef Link).

[20] L. Dipietro, M. Ferraro, J. Palazzolo, H. Krebs, B. Volpe and N. Hogan, "Customized Interactive Robotic Treatment for Stroke EMG Triggered Therapy," IEEE Transactions on Neural Systems and Rehabilitation Engineering, Vol. 13, No. 3, pp. 325-334, September, 2005. Article (CrossRef Link).

[21] M. Liarokapis, P. Artemiadis and K. Kyriakopoulos, "Task discrimination from myoelectric activity: A learning scheme for EMG-based interfaces," in Proc. of 2013 IEEE International Conference on Rehabilitation Robotics (ICORR), pp. 1-6, October, 2013. Article (CrossRef Link). 
[22] A. Shabani and M. Mahjoob, "Bio-signal interface for knee rehabilitation robot utilizing EMG signals of thigh muscles," in Proc. of 2016 4th International Conference on Robotics and Mechatronics (ICROM), pp. 228-233, March, 2016. Article (CrossRef Link).

[23] C. Cousin, C. Rouse, V. Duenas and W. Dixon, " Position and torque control via rehabilitation robot and functional electrical stimulation," in Proc. of 2017 International Conference on Rehabilitation Robotics (ICORR), pp. 38-43, July, 2017. Article (CrossRef Link).

[24] S. Sidek, H. Rosly, H. Yusof, A. Puzi, N. Daud and M. Rosly, "Modified Ashworth Scale (MAS) integrated adaptive impedance control framework for upper extremity training platform," in Proc. of 2017 IEEE International Conference on Mechatronics and Automation (ICMA), pp. 893-898, August, 2017. Article (CrossRef Link).

[25] I. Zaidi, M. Chtourou and M. Djemel, "Sliding mode backpropagation training algorithm for robust neural control of discrete time uncertain nonlinear systems," in Proc. of 2016 5th International Conference on Systems and Control (ICSC), pp. 115-119, July, 2016. Article (CrossRef Link).

[26] M. Luck and d. Mark, "A Conceptual Framework for Agent Definition and Development," The Computer Journal, Vol. 44, No. 1, pp. 1-20, January, 2001. Article (CrossRef Link).
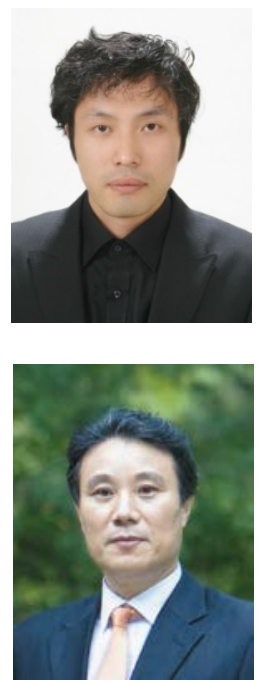

Taeyeun Kim received the B.S, M.S. and Ph.D. degrees from Department of Computer Science and Statistics from Chosun University, Gwangju, Korea, in 2002, 2005, and 2015 respectively. From 2012 to 2015, He has been a senior researcher with Shinhan Systems Corp.. He is currently working as a researcher at the same university. Him research interests include artificial intelligence, bioinformatics, smart grid computing and IoT.

Sanghyun Bae received the B.S. and M.S. degrees from the Department of Electrical Engineering at Chosun University, Gwangju, Korea, in 1982 and 1984, and Ph.D. degree from the Department of Information Science at Tokyo Metropolitan University, Tokyo, Japan, in 1988, respectively. He was a researcher in the Department of Electrical Engineering at Tokyo Institute of Technology, Japan in 1985. Also, he was a visiting professor in the Department of Information Engineering at Nara Institute of Technology, Japan in 1997 and the Department of Information Engineering at University of Alberta, Canada in 2002 and a member of board of directors of NRF, Korea in 2012-2013. He is a professor in the Department of Computer Science and Statistics at Chosun University, Gwangju, Korea. 